\title{
Women in Punjab are in Dire Need of Awareness Initiatives Related to Cervical Cancer and its Screening Tests
}

\author{
ZERTAJ KASHIF ${ }^{1}$, AMAN UR REHMAN ${ }^{2}$, SONIA ZAFAR WARRIACH ${ }^{3}$, MUHAMMAD BILAL PASHA $^{4}$, ZOYA KHAN ${ }^{5}$, \\ SEHAR BASHIR ${ }^{6}$ \\ ${ }^{1}$ FCPS Histopathology, Associate Professor, Bakhtawar Amin Medical \& Dental College, Multan \\ ${ }^{2}$ Professor and Head of Histopathology Department, Shaikh Zayed Hospital Lahore \\ ${ }^{3}$ FCPS Obstetrics and Gynaecology, DHQ Jhang \\ ${ }^{4}$ MBBS; M Phil Pathology, FCPS Histopathology (II), Assistant Professor, Bakhtawar Amin Medical \& Dental College, Multan \\ ${ }^{5}$ Demonstrator, Multan Medical \& Dental College \\ ${ }^{6}$ MBBS, M Phil Haematology (Part II), Demonstrator, Bakhtawar Amin Medical \& Dental College, Multan \\ Correspondence to: Dr. Zertaj Kashif, Email: zkashif786@icloud.com, Cell: 03146121201
}

\begin{abstract}
Cervical cancer is the third most common cancer and the fourth dominant cause of cancer related death in women throughout the globe. Eighty percent of cases occur in the developing nations ${ }^{1,2}$. The extent of this cancer is tough to be evaluated in Pakistanbecause of differing insufficient epidemiological figures obtainable in small scale studies, dealing only reported limited number of cases which are not representative of its true burden ${ }^{3,4,5}$. As stated by World Health Organization, in 2002, the pervasiveness of cervical cancer in Pakistan was 9 in 100,000; in 2008 it jumped up to 19.5/100,000. Claimed by various studies, this cancer is among the list of first ten frequent cancers in Pakistan $6,7,8,9$. It is one of the most avoidable cancers nowadays and we have all the tools to eradicate it, still the number of lives lost due to cervical cancer is very high in Pakistan as it is an ignored ailment here in terms of screening, prevention and vaccination ${ }^{9}$.

Economically developed countries who invested capitals for organized screening projects have made notable progress in reducing both occurrence and mortality due to this specific cancer ${ }^{10}$. The out of proportion load of cervical cancer in developing countries is largely attributable to scarcity of functional screening projects ${ }^{11}$. In our over 500 bedded teaching hospital with a well running gynecology outdoor, we do receive cervical biopsies positive for invasive malignancies but hardly receive any Pap smear tests in laboratory that prompted us to check for cervical cancer screening especially Pap smear test related awareness among our non-medical ladies. As the foundation of cervical cancer eradication is screening and prevention, each country and its regions must device an elimination plan that fits into its own culture and geographic landscape.
\end{abstract}

Keywords: perception and understanding of existing screening tests, preventive measures, cervical cancer

\section{INTRODUCTION}

The cervix is the lower end of the uterus and cervical carcinoma is an abnormal rapid growth of neoplastic cells of the cervix ${ }^{13}$. It is the fourth most common cancer in women of all age groups globally.9,14

The incidence announced by WHO in 2018 is $570,000,7.5 \%$ of cancer related female deaths indicating cervical carcinoma costs a life every two minutes worldwide. ${ }^{14,15}$

South Asian countries account for one third of the entire disease load, though $85 \%$ of all reported deaths due to this cancer, turned up in developing nations. ${ }^{14,16}$

Pakistan is one of the top ten countries with the highest female death rates; daily almost 20 women are identified with cervical carcinoma so here the condition is even worse. ${ }^{8}$

Cervical carcinoma is usually asymptomatic in its early stages where Pap smear screening could help in early diagnosis. Considering the various risk factors like smoking, early age at marriage, high parity, poor personal hygiene, low socioeconomic status and estrogen exposure in the form of oral contraceptive pills for longer periods, women of Pakistan and different regions are prone to

Received on 03-03-2021

Accepted on 21-05-2021 develop cervical carcinoma. Human Papilloma virus (HPV) is a well known causative agent in almost all cases of cervical cancer all over the world; more than $75 \%$ of sexually active adults have had HPV infection in their lifetime ${ }^{16,17}$.

In spite of having all the tools to prevent and cure cervical carcinoma at an early stage, Though cervical carcinoma is absolutely preventable and curable at an early stage, it is quite alarming that more than one third of all women diagnosed with it eventually die and almost $50-90 \%$ of these ladies have never been screened. ${ }^{14,18,19}$

The situation is even worse in various regions of Pakistan. However, using prophylactic precautionary programs like Pap smear screening and HPV vaccination, the prevalence of precancerous and invasive cervical carcinomas can be successfully managed in $75 \%-90 \% .{ }^{14,20}$

It is mostly assumed that the educational and socioeconomic standing can affect the perspective and understanding of risk factors and screening implementations of females, eventually minimizing the probability of HPV induced cervical cancers. Thus, this study was carried out to assess various variables that may affect the attitudes and perceptions of ladies belonging to divergent socioeconomic status in Pakistan with reference to cervical carcinoma. 


\section{MATERIALS AND METHODS}

A questionnaire based on survey, using face to face exchange was regulated between August 2019 to February 2021 in districts Multan and Lahore. Females aged 16 years and above were approached in different OPDs of Bakhtawar Amin Hospital Multan, Shaikh Zayed Hospital Lahore, as well as public sites of the districts (markets, malls, restaurants, parlor, gym, public parks and gardens etc) to amplify the probability of covering women from divergent social groups. Non medical female members of medical professionals are also included. Informed consent was taken from all the participants and their confidentiality was kept. A total of 480 women agreed to voluntarily participate in the study.

The questionnaire was outlined considering objectives of the survey after going through the pertinent data available on the topic. It was translated into Urdu language and then back to English for quality assurance. The questionnaire was divided into two main sections, first dealing with the sociodemographic particulars of the participants (e.g. age, education, occupation etc) and second half regarding awareness, knowledge and information sources of cervical carcinoma, Pap smear screening test and HPV. Percentage and proportions were calculated for all the variables. Relevant tables and charts were computed.

\section{RESULTS}

A sum of 480 women participated in this survey. Majority of them were between ages 18 to 39 years. Majority of the participants $(82.5 \%)$ were married. We tried to cover women with low or no education (almost $40 \%$ ) and highly educated women (almost 60\%) in our survey as shown in table 3; also women belonging to various socioeconomic status: low (43\%), medium (30\%), and high (27\%). Out of 480 women, 216 were housewives, 184 were employed and 80 were students. The working ladies were mostly teachers, receptionists, maids, tailor and security guard.

Out of these 480 participants, only 40 women were having knowledge regarding cervical cancer, 35 had idea of Pap smear screening test and only 29 women knew about HPV. Only 6 women out of these 480 ever underwent Pap smear test and that too only once in their life and on recommendation of their doctors because of some gynecological ailment. Those who were familiar with cervical cancer and pap smear, acquired information either from their doctors or their family and friends who contracted the disease. The main reasons reported by the educated and high socioeconomic status participants who heard of Pap screening test but never have been screened were either their negligence, felling of embarrassment and fear of pain. For others financial reasons and fear of getting some grave disease were on top.

Even after providing detailed information regarding cervical cancer, 174 (only educated) ladies showed willingness to go for Pap smear test; however, 297 ladies said that they would like to have HPV vaccine especially if government provides it free of cost.

\section{Demographic Characteristic}

Table 1

\begin{tabular}{|l|c|c|}
\hline Age (Years) & Number & Percentage \\
\hline $18-29$ & 192 & 40 \\
\hline $30-39$ & 153 & 31.9 \\
\hline $40-49$ & 79 & 16.5 \\
\hline$>50$ & 56 & 11.6 \\
\hline Total & 480 & 100 \\
\hline
\end{tabular}

Table 2

\begin{tabular}{|l|c|c|}
\hline Occupation & Number & Percentage \\
\hline Student & 80 & 16.7 \\
\hline Housewife/retired & 216 & 45 \\
\hline Employed & 184 & 38.3 \\
\hline Total & 480 & 100 \\
\hline
\end{tabular}

Table 3

\begin{tabular}{|l|c|c|}
\hline Education & Number & Percentage \\
\hline Uneducated/illiterate & 144 & 30 \\
\hline Primary school & 49 & 10.2 \\
\hline Secondary school & 45 & 9.4 \\
\hline College/university & 242 & 50.4 \\
\hline Total & 480 & 100 \\
\hline
\end{tabular}

Table 4
\begin{tabular}{|l|c|c|}
\hline Monthly Income & Number & Percentage \\
\hline Low & 208 & 43 \\
\hline Medium & 144 & 30 \\
\hline High & 128 & 27 \\
\hline Total & 480 & 100 \\
\hline
\end{tabular}

Table 5

\begin{tabular}{|l|l|l|}
\hline Parity & Number & Percentage \\
\hline Nulliparous & $152+84$ unmarried $=236$ & $32+17.5=49.5$ \\
\hline With one child & 48 & 10 \\
\hline Multipara 2-3 & 48 & 17.5 \\
\hline $\begin{array}{l}\text { Grand multipara } \\
\text { 4 and more }\end{array}$ & 112 & 23 \\
\hline Total & 480 & 100 \\
\hline
\end{tabular}

Participant's awareness regarding cervical cancer, Pap smear and HPV

\begin{tabular}{|l|l|l|}
\hline Ever heard of Cervical cancer & Number & Percentage \\
\hline Yes & 40 & 8.3 \\
\hline No & 440 & 91.7 \\
\hline Ever heard of Pap smear & 35 & 7.3 \\
\hline Yes & 445 & 92.7 \\
\hline No & 29 & 6 \\
\hline Ever Heard of HPV & 451 & 94 \\
\hline Yes & 6 & 1.3 \\
\hline No & 474 \\
\hline Ever undergone Pap smear test & 98.7 \\
\hline Yes & 174 \\
\hline No & 306 & 36.3 \\
\hline Would like to undergo Pap smear test now & 63.7 \\
\hline Yes & \multicolumn{1}{|l|}{} \\
\hline No & 297 & 62 \\
\hline Would like to have HPV Vaccine now & 38 \\
\hline Yes & 183 \\
\hline No
\end{tabular}




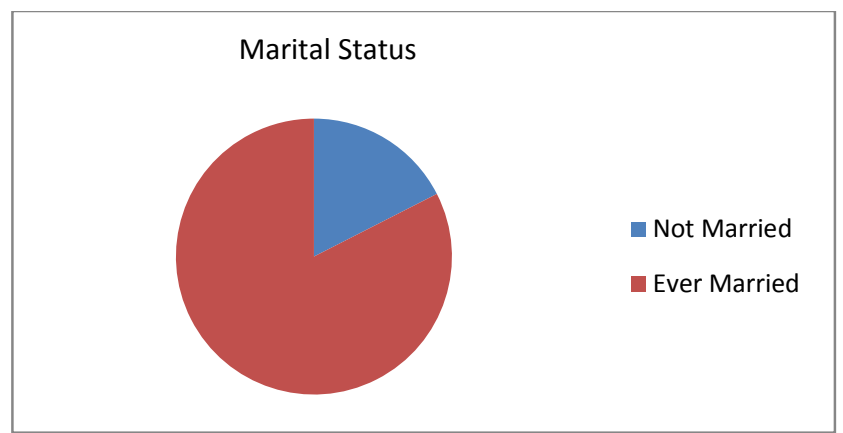

\section{DISCUSSION}

This study is done to find out the level of understanding and awareness of cervical cancer, Pap smear test and HPV in women of Multan and Lahore. The findings indicate a very poor level of knowledge. Total number of women in our study was 480 . Out of these, only $40(8.3 \%)$ had some information about cervical carcinoma. The women who were aware of Pap smear screening were $35(7.3 \%)$ and only $29(6 \%)$ knew about HPV. Out of these, just $1.3 \%$ (06/480) ever had Pap smear test. These findings are consistent with a number of other studies conducted in various cities of Pakistan and other developing countries $^{21,22,23}$

The results are not shocking at all as no efforts are made in this region to inform general population about this particular cancer and its available screening tests and vaccination.

The most common reasons according to our survey among these participants were negligence and lack of awareness followed by financial reason in poor families. This is consistent with results of studies conducted by Sultana $R$ et al and Gebru $Z$ et $a^{21,24}$. According to Tripathi et al $83.9 \%$ participants had no information followed by economic constrains in $3.9 \%$.

In our study majority(almost $75 \%$ ) of women were between ages 18 to 39 years in concordance to study conducted by Jafri $\mathrm{A} A$ et $\mathrm{al}^{26}$ in which $84 \%$ of women were between ages 18 to 40 years with mean age 32.5 years. According to their study, conducted in (OB/GYN OPD) in tertiary care setting of Military Hospital and Combined Military Hospital, Rawalpindi forty five percent of patients have heard about cervical cancer, $20 \%$ had heard about HPV and Pap smear and $22 \%$ had some degree of information regarding HPV vaccine and according to their article there is significant association of socioeconomic status and education with knowledge of cervical cancer, pap smear and HPV vaccine but in our study all women were equally unaware of cervical cancer, Pap smear and HPV irrespective of their qualification, dependency and socioeconomic status in concordance to study conducted by Sultana $R$ et $a^{21}$.

The only difference we established based on education is the willingness of 174 educated ladies in our study to go for Pap smear test. Almost all illiterate women in our survey didn't show any inclination towards Pap smear test or HPV vaccination even after providing detailed information regarding cervical cancer and its mortality due to late presentation, which divulge the absolute need to enlighten the women of Multan and Lahore about this cancer and its available screening and vaccination programs.

\section{CONCLUSION}

This study spotlights the paucity of knowledge regarding cervical cancer in women and absolute need to improve their health seeking attitudes and to boost early screening rates. Guidance through health care providers and educational campaigns involving media might help in this regard.

\section{REFERENCES}

1. Jemal A, Center MM, DeSantis C, Ward EM. Global Patterns of Cancer Incidence and Mortality Rates and Trends. Cancer Epidemiol Biomarkers Prev. 2010; 19: 1893-907

2. Moosa NY, Khattak N, Alam MI, Sher A, Shah W, Mobashar $\mathrm{S}$, et al. Comparison of cervical cell morphology using two different cytology techniques for early detection of precancerous lesions. Asian Pac J Cancer Prev. 2014; 15:97581.

3. Aziz Z, Sana S, Saeed S, Akram M. Institution based tumor registry from Punjab: five year data based analysis. J Pak Med Assoc. 2003; 53:350-353

4. Badar F, Anwar N, Meerza F, Sultan F. Cervical carcinoma in a Muslim community. Asian Pac J Cancer Prev. 2007; 8:24-26

5. Bhurgri Y. Karachi Cancer Registry Data-implications for the National Cancer Control Program of Pakistan. Asian Pac J Cancer Prev. 2004;5: 77-82.

6. Bhurgri Y, Bhurgri A, Pervez S, Bhurgri M, Kayani N, Ahmad R, et al. Cancer profile of Hyderabad, Pakistan, 1998-2002. Asian Pac J Cancer Prev. 2005; 6:474-80.

7. Bhurgri Y, Nazir K, Shaheen Y, Usman A, Faridi N, Bhurgri $\mathrm{H}$, et al. Time trends in the incidence of Cancer Cervix in Karachi South. Asian Pac J Cancer Prev. 2007; 8:357-62.

8. Kamal R. Pap smear. The Life-Saving Test. The Express Turbine. 2014 Nov 17.

9. Batool S A, Sajjad S, Malik H. Cervical cancer in Pakistan: A review. Journal of Pakistan Medical Association. 2017. 67:1074-77

10. Musa J. The need for Societal Investment to improve Cervical Cancer Outcomes in Nigeria: A commentary. 2017; 21: 17-23.

11. Hristova I, Hakama M. Effect of screening for cancer in Nordic countries on deaths, cost and quality of life up to the year 2017. Acta Oncol. 1997; 36 Suppl 9: 1-60.

12. Ann Marie Beddoe. Elimination of cervical cancer: challenge for developing countries. 2019; 13:975.

13. Mishra K: Gynaecological malignancies from palliative care perspective. Indian J Palliat Care. 2011, 17: S45-51.

14. Human papillomavirus (HPV) and cervical cancer. 2019. https://www.who.int/news-room/fact-sheets/detail/humanpapillomavirus-(hpv)-and-cervical-cancer.

15. Schoueri-Mychasiw N, McDonald PW: Factors associated with underscreening for cervical cancer among women in Canada. Asian Pac J Cancer Prev. 2013, 14: 6445-50.

16. Raychaudhuri S, Mandal S: Current status of knowledge, attitude and practice (KAP) and screening for cervical cancer in countries at different levels of development. Asian Pac J Cancer Prev. 2012, 13:4221-27.

17. Koutsky L. Epidemiology of Genital Human Papillomavirus Infection. Am J Med. 1997; 102(5): 3-8.

18. Daniyal M, Akhtar N, Ahmad S, Fatima U, Akram M, Asif $\mathrm{HM}$ : Update knowledge on cervical cancer incidence and prevelance in Asia. Asian Pac J Cancer Prev.2015, 16: 3617-3620. 
19. Owoeye IOG, Ibrahim IA: Knowledge and attitude towards cervical cancer screening among female students and staff in a tertiary institution in the Niger Delta. Int $\mathrm{J}$ Med Biomed Res. 2013, 2:48-56.

20. Riaz L, Manazir S, Jawed F, et al. March 2020. Knowledge, Perception and Prevention Practices Related to Human Papillomavirus-based Cervical Cancer and its Socioeconomic Correlates among Women in Karachi, Pakistan. Cureus 12(3)

21. Sultana R, Hafeez M, Shafiq S. AWARENESS ABOUT CERVICAL CANCER IN PAKISTANI WOMEN. Pak Armed Forces Med J 2019; 69 (1): 21-25.

22. Khan G J, Naeem H S, Khan S, Jamshaid T, Sajid MI, Bashir I, Jamshaid M. Understanding and responsiveness level about cervical cancer and its avoidance among young women of Pakistan. Asian Pa ,Mc J Cancer Prev. 2014; 15(12): 4877-83.

23. MeghaPrakash, G.S. Jyothi, N.S. Murthy. Awareness of Pap test among women at a tertiary center in Bangalore, India. Proceedings in Obstetrics and Gynecology, 2015;5(1):1

24. Gebru Z, Gerbaba M, Dirar A. Barriers to cervical screening in Arba Minch Town, Southern Ethiopia: A Qualitative Study. J Community Med Health 2016; 6(1): 1-5.

25. Tripathi N, Kadam YR, Dhobale RV, Gore AD. Barriers for early detection of cancer amongst Indian rural women. South Asian J Cancer 2014; 3(2): 122-7.

26. Jafri A A, Shah AY, Shamim Z, Choudhry A, Bajwa A A. Awareness and knowledge Regarding Cervical Cancer Screening and its Association with Demographic Characteristics. Ann Pak Inst Med Sci. 2018;14(4): 285-290. 